\title{
Parental control in interpersonal acceptance-rejection theory: a study with a Spanish sample using Parents' Version of Parental Acceptation-Rejection/Control Questionnaire
}

\author{
Carmen-María Fernández-García*, Carmen Rodríguez-Menéndez and José-Vicente Peña-Calvo
}

Facultad de Formación del Profesorado y Educación. Departamento de Ciencias de la Educación. University of Oviedo (Spain).

\begin{abstract}
Título: Control parental en la teoría de la aceptación-rechazo interpersonal: un estudio con una muestra española usando la Versión de los Padres del Cuestionario de Aceptación / Control Parental.

Resumen: Control parental en la teoría de la aceptación-rechazo interpersonal: un estudio con una muestra española usando la Versión de los Padres del Cuestionario de Aceptación / Control Parental.

La teoría de la aceptación - rechazo interpersonal (IPART) proporciona un adecuado marco teórico para explicar las diversas dimensiones parentales que influencian el ajuste social, cognitivo y emocional de los niños. En efecto, esta teoría desarrolla una dimensión principal, cariño - rechazo, en la que el cariño se encontraría situado en un extremo del continuo y el rechazo en el opuesto. Además, esta teoría también define el control parental tomando como referencia dos polos: el control permisivo y el restrictivo. En el contexto de esta teoría, nuestro estudio ha sido llevado a cabo con una muestra de padres para (a) examinar en qué medida los padres y las madres perciben la aceptación - rechazo como elementos integrantes de su comportamiento de control parental (b) analizar cómo funciona la dimensión control dentro de la teoría IPART (c) examinar si se observan diferencias en las relaciones observadas en los padres y en las madres. Se concluye que el control de conductas correlaciona positivamente con las conductas de cariño. Las correlaciones de padres y madres en estas dimensiones muestran que los padres pueden desarrollar ciertos comportamientos de control pero que éstos son compatibles con las conductas afectivas.

Palabras clave: teoría de la aceptación - rechazo interpersonal; cariño- rechazo; control; modelo de ecuaciones estructurales.
\end{abstract}

\section{Introduction}

No one seems to doubt that the family is the most important reference during the first years of children's life. In this environment, boys and girls learn their first skills and habits which will allow them to become autonomous. In this sense, families should stimulate the autonomy and freedom of their members, must reconcile individuality with community and solidarity, as well as autonomy with interdependence. Thus, they do not only offer care but also teach how to live in a society and help in the development of boys' and girls' personalities. Moreover, children have to learn about the limitations and possibilities they will face with in their future. They will also need to control their impulses and learn certain roles to express themselves considering the existence of others.

In this context, the Interpersonal Acceptance-Rejection theory (IPARTheory) provides a good theoretical framework to explain the parenting dimensions that influence social, cognitive and emotional children's adjustment. So, this theory postulates a universal relation between perceived parental acceptance-rejection and individuals' psychological adjust-

$*$ Correspondence address [Dirección para correspondencia]:

Carmen-María Fernández-García. Facultad de Formación del Profesorado y Educación. Departamento de Ciencias de la Educación. Despacho 235 C/ Aniceto Sela, s.n. 33005. Oviedo (Spain).

E-mail: fernandezcarmen@uniovi.es

\begin{abstract}
Interpersonal Acceptance-Rejection theory (IPARTheory) provides a good theoretical framework to explain the parenting dimensions that influence children's social, cognitive and emotional adjustment. This theory develops one main dimension, warmth-rejection, where warmth would be one pole of the dimension and rejection the opposite one. Besides, the theory has also defined behavioral control dimension with two poles: permissiveness-strictness. In the context of this theory, our study was conducted with a sample of Spanish parents to (a) examine whether parental perceived acceptance-rejection was related to parental behavioral control; (2) analyze how behavioral control dimension worked in acceptance-rejection theory; and (3) examine whether there were differences in the relations obtained between fathers and mothers. We have to conclude that control behavior correlates positively with warmth behaviors. Fathers' and mothers' correlations among these dimensions show that parents can develop certain control behaviors but that they are compatible with affection conducts.

Key words: Interpersonal Acceptance-Rejection theory; warmth-rejection; control; structural equation modelling.
\end{abstract}

ment in childhood (Khaleque \& Rohner, 2002b). Specifically, IPARTheory indicates that children are phylogenetically predisposed to develop a specific constellation of personality dispositions as a result of experiencing varying degrees of parental acceptance or rejection (Rohner, Khaleque \& Courneyer, 2005). IPARTheory develops one main dimension, warmth-rejection, where warmth would be one pole and rejection the opposite one. Besides, Rohner's model has also defined "behavioral control dimension" which is related with warmth-rejection dimension. Behavioral control is based on two poles: permissiveness-strictness (Rohner \& Khaleque, 2008).

In relation to these two dimensions and as result of a research with 4168 parents from the Principality of Asturias (Spain), the current paper provides a conceptual framework that specifies the linkages between the central dimensions of parenting in IPARTheory (warmth-rejection and behavioral control).

\section{Interpersonal acceptance-rejection theory (IPAR- Theory): the warmth-rejection dimension}

IPARTheory is an evidence-based theory of socialization and life span development that aims to explain the major causes, consequences, and other correlates of interpersonal acceptance-rejection worldwide (Ali, Khaleque \& Rohner, 2014). Regarding the relationships between children and 
their parents, this theory analyzes the antecedents, consequences, and other correlates of parental acceptance and rejection (Khaleque \& Rohner, 2002a, 2002b; Rohner, Khaleque \& Cournoyer, 2005; Rohner \& Khaleque, 2002).

As we have already stated, the main dimension of this theory is warmth-rejection. Parental acceptance and rejection form the warmth dimension of parenting. This is a dimension or continuum on which all humans can be placed as long as everyone has experienced more or less love at the hands of major caregivers during their childhood (Rohner et al., 2005). One end of the continuum is marked by parental acceptance, which refers to the affection, care, support that children can experience from their parents and other caregivers. The other end of the continuum is marked by parental rejection, which refers to the absence or significant withdrawal of these feelings and behaviors. Cross-cultural research reveals that parental acceptance-rejection can be experienced by any combination of the following four expressions: 1) cold and unaffectionate (the opposite of being warm and affectionate); 2) hostile and aggressive; 3) indifferent and neglecting; and 4) undifferentiated rejecting (Rohner et al., 2005).

Parental acceptance for children can be expressed in various ways. Supportive parents, for example, express interest in their children's activities and opinions; talk with them about their feelings and emotions; show psychical affection and love; provide comfort, moral guidance, and advice; take part in social activities with them; listen to them carefully and help them to solve their problems. Research in the field of parenting styles has demonstrated that parental acceptance has been linked to positive mental health, social competence, self-esteem, academic achievements, and healthy peer relationships (McNeely \& Barber, 2010. Also see Bean, Barber \& Crane, 2006; Boudreault-Bouchard et al., 2013; Ferguson, Kasser \& Jahng, 2010; Grolnick et al., 2015; Pastorelli et al., 2016). Besides, the indulgent style, characterized by warmth but not strictness, and the authoritative style, characterized by warmth and strictness, were found to be more associated with better outcomes than the authoritarian style, characterized by strictness and no warmth (Calafat et al., 2014; Fuentes, et al., 2015; García \& Gracia, 2009, 2010).

Likewise, of the three dimensions of parenting (parental support, psychological control, behavioral control) studied in Barber, Stolz, Olsen, Collins \& Burchinal (2005), perceived parental support seems to be the most relevant one in order to understand adolescent's psychosocial functioning.

In the specific field of the IPARTheory, different metaanalytic studies have been developed by Rohner's research team to test the major postulates of parental acceptancerejection theory. In the first meta-analysis the results concluded that perceived parental acceptance-rejection is pan culturally associated with a specific constellation of personality dispositions that reveal one's psychological adjustment state (Khaleque \& Rohner, 2002a). In the second metaanalysis of cross-cultural and intercultural studies, it was concluded that perceived parental acceptance-rejection was transculturally associated with roughly $26 \%$ of the variance in children's self-reported psychological adjustment (Khaleque \& Rohner, 2002b). The third meta-analysis showed that the less accepting (or more rejecting) men and women remember their mothers and fathers during their childhood, the more psychologically maladjusted they tend to be (Rohner \& Khaleque, 2010).

Furthermore, the four meta-analytic studies supported most of the IPARTheory's postulates about the associations between the experience of parental acceptance-rejection in childhood and seven personality dispositions involving hostility, independence, self-esteem, self-adequacy, emotional stability, emotional responsiveness, and worldview (Khaleque \& Rohner, 2012a). The fifth meta-analytic review showed strong relationships between perceived parental acceptance and children's and adults' psychological adjustment across cultures (Khaleque \& Rohner, 2012b). Finally, the latest meta-analysis of cross-cultural studies concluded that maternal and paternal as well as teacher acceptance correlated significantly with youth's psychological adjustment and school conduct (Ali et al., 2014). To sum up, the research has indicated that showing love and assisting children to feel better is extremely important for their psychological adjustment.

\section{Interpersonal acceptance-rejection theory (IPAR- Theory): the behavioral control dimension}

Behavioral control is another crucial dimension in interpersonal acceptance-rejection theory. It has been found that parental acceptance predicts psychological adjustment in children. However, the influence of the control dimension on children's psychological adjustment is unclear. In addition, parental control dimension has been less studied than parental acceptance dimension.

Moreover, although the majority of the research about parenting styles supports that parental control is important in the prevention of children's and adolescents' behavioral problems, there is not a definite agreement with this conclusion. In this sense, studies about parenting styles which have been developed in recent years found that the indulgent style, characterized by warmth but not strictness, was as effective as the authoritative style, characterized by warmth and strictness, or even more effective, on the prevention of psychological maladjustment on adolescence. So, Calafat et al. (2014) found that in the European context the indulgent parenting performs as well as the authoritative style on scores about substance use and personal disturbances, and indulgent parenting performs better than authoritative style on scores about self-esteem and performance. Similar results were found by Fuentes et al. (2015) who revealed that in their study adolescents from indulgent families showed the lowest consumption in the evaluated substances (alcohol, tobacco, cannabis and other drugs).

The results obtained by García \& Gracia (2009) were similar in relation to self-esteem, psychosocial maladjust- 
ment, school misconduct, delinquency, and drug use in a sample with teenagers from 12 to 17 years old. Finally, the same authors found similar results with children and adolescents from 10 to 14 years old for the following variables: self-esteem, psychological adjustment, social competence, and behavioral problems (García \& Gracia, 2010).

Nevertheless, other researches have concluded that control positively affects the children's behavior when it refers to educational supervision strategies and that this dimension is associated with the presence of behavioral and emotional problems when intrusive strategies are used in order to control the behavior. In this sense, some investigations explain that the control dimension can be separated in two distinct forms: behavioral and psychological control. So, behavioral control refers to the provision of regulation or structure to the child's behavioral world. In contrast, psychological control refers to intrusion and manipulation of the children through strategies such as constraining verbal interactions, invalidation of feelings, or induction of feelings of guilt (Bean et al., 2006).

From this perspective, researches have demonstrated that psychological control is a predictor of internalizing and externalizing problems in adolescence (Bean \& Northrup, 2009; Boudreault-Bouchard et al., 2013; Gargurevich \& Soenens, 2016) and in children (Stone et al., 2013). In addition, studies have also showed a negative relation between behavioral control and emotional and behavioral problems in children and youths (Arin, Marshall \& Shapka, 2010; Arin \& Shapka, 2008; Bean et al., 2006; Betancourt \& Andrade, 2011; Grolnick et al., 2015; Lansford, Laird, Pettit, Bates \& Dodge, 2014; Pettit, Laird, Dodge, Bates \& Criss, 2001; Wijsbroek, Hale III, Raaijmakers \& Meeus, 2011).

In relation to interpersonal acceptance-rejection theory, this control dimension has been called "behavioral control dimension" (permissiveness-strictness). This dimension refers to the attempts made by parents to regulate, manipulate, or manage their children's behavior. Furthermore, the concept of behavioral control involves the extent to which parents insist on compliance with their demands, directives, rules, prescriptions, and proscriptions (Rohner \& Khaleque, 2008).

In summary, the present study has been conducted with a sample of Spanish parents to state their educational styles and define the role of control in acceptance-rejection dimension. More specifically, the purpose of the study was to (a) examine whether parental perceived acceptance-rejection is related to the parental behavioral control; (2) analyze how behavioral control dimension worked in acceptance-rejection theory; and (3) examine whether there are differences between fathers and mothers in the relations obtained. In this sense, it must be said that as long as there are no previous studies that analyze the relation between warmth-rejection dimension and behavioral control dimension, our study helps to develop the IPARTheory. With this purpose in mind, we administered Parent PARQ/Control (mother's and father's version).

\section{Method}

\section{Participants}

The participants were 4,168 fathers and mothers from the Principality of Asturias (2,002 fathers, $48 \%$ of the sample and 2,166 mothers, $52 \%$ of the sample). The mean age for fathers was 41.90 years $(S D=6.70)$ and 39.50 years for mothers $(S D=5.95)$. There were significant differences in fathers' and mothers' ages $(Z=-11.51, p<.001)$. The mean number of children by family was two. $1,301(31.2 \%)$ of the parents had children who attended nursery schools/kindergartens and 2,510 (60.2\%) attended Elementary schools. In 357 cases these data were not indicated.

If we focus on parents whose children were in early childhood education: 420 of them had children in nursery schools (3 years old), 391 in kindergarten (4 years old) and 467 in kindergarten ( 5 years old). On the other hand, referring to parents whose children were studying Primary education: 454 of them had children in the first grade, 441 in the second grade, 346 in the third, 404 in the fourth, 473 in the fifth and 390 in the sixth. Regarding children's gender, 2,002 were boys (48\%) and 2,081 girls (50.9\%). The sample had homogeneous ethnical characteristics. In terms of parents' educational level, the average was secondary education both for fathers and mothers. $46.1 \%$ of the parents had skilled occupations (doctors, teachers, managers, etc.) and 53.9\% semi-skilled occupations.

\section{Instruments}

Parental Acceptation Rejection/Control Questionnaire (parent version)-Parent PARQ/Control- (Rohner \& Khaleque, 2008) is a scale that includes 29 items assessing the acceptationrejection and controlling behavior practiced by parents with their children $(4=$ almost always true to $1=$ almost never true). Rohner's formal authorization to adapt the instrument to our region was obtained first of all. The Spanish version of professor Carrasco which includes two versions (one for father and another one for the mother) has been used in this study (Rohner \& Carrasco, 2014). The original version included the following factors: warmth/affection (8 items), hostility/aggression (6 items), indifference/neglect (6 items), undifferentiated rejection (4 items) and control (5 items).

In the original version, the alpha coefficient for the total PARQ was between .78 and .88 for mother's version whereas in our sample it was .79. In the father's version, internal consistency was .84 and in our sample .83. In Parent PARQ/Control (mothers' version) warmth/affection had an $a$ between .78 and .87 , hostility/aggression between .78 and .87 , indifference/neglect between .52 and .69 and undifference/rejection between .53 to .69. Data for Parent PARQ/Control (fathers' version) are not available (Rohner, 2008a). In other versions of PARQ, the alpha values for warmth/affection were .97 (Adult Father PARQ) and .95 (Child Father PARQ). The hostility/aggression dimension had an $a$ value of .87 (PARQ Adult Father) and .91 (PARQ 
Child Father). In indifference/neglect alpha values were .91 (PARQ Adult Father) and .86 (PARQ Child Father). Finally in undifference/rejection the alpha values were .88 (PARQ Adult Father) and .76 (PARQ Child Father).

Table 1 shows alpha values for our sample. Indifference/neglect dimension was translated in the Spanish version in the reversed way. For example, item 2 is formulated in the original version: "I pay no attention to my child", and in the Spanish one "Presto atención a mi hijo/a" [I pay attention to my child]. Another example could be item 13: "I pay no attention to my child when (s)he asks for help", which in the Spanish version is: "Presto atención a mi hijo/a cuando me pide ayuda" [I pay attention to my child when (s)he asks for help]. This is a very important point in order to interpret the sense of this factor, as long as the factorial analyses have showed that this dimension assesses no neglect parental behaviors.

Table 1. Description of the dimensions of PARENT PARQ/Control.

\begin{tabular}{lcccc}
\hline \multirow{2}{*}{ Dimensions } & \multicolumn{2}{c}{ Number of items } & \multicolumn{2}{c}{$\begin{array}{c}\text { Cronbach } \\
\text { Alpha Values }\end{array}$} \\
\cline { 2 - 5 } & Mothers & Fathers & Mothers & Fathers \\
\hline Warmth/affection & 9 & 6 & .83 & .81 \\
Hostility/aggression & 3 & 7 & .63 & .70 \\
No Indifference/no neglect ${ }^{\text {a. }}$ & & 4 & & .81 \\
Control & 4 & 3 & .70 & .65 \\
\hline
\end{tabular}

a. Indifference/neglect was not present in mother's factorial structure. Note: Undifference/rejection dimension dropped out from factorial structure in mothers and fathers.

The control dimension was originally measured with "The Parental Control Scale (PCS)" (Rohner \& Khaleque, 2008). After the original authors adapted it in a scale of eight items, the alpha value for this dimension was between .62 and .74 for the mother's version and .71 for the father's one (Rohner \& Khaleque, 2008). Five new items with an internal consistency of .74 have been included in the version used in the present study (Rohner, 2008b). Table 2 shows a sample of items for each factor.

Table 2. Parent PARQ/Control (Short Form): sample of items.

Warmth/affection

I say nice things about my child (.48/.41)

I make it easy for my child to confide in me $(.53 / .37)$

I make my child feel wanted and needed (.79/.69)

Hostility/aggression,

I hit my child, even when (s)he does not deserve it $(.52 / .43)$

I punish my child severely when I am angry (.61/.39)

When my child makes something wrong, I frighten or threaten him/her $(.42 / .51)$

No Indifference/ no neglect

I pay attention to my child (/.86)

I am too busy to answer my child's questions (//-.51)

I take real interest in my child's affairs (/.39)

Control

I always tell my child how (s)he should behave (.57/.77)

I insist that my child does exactly as (s)he is told (.64/.66)

I want to control whatever my child does $(.50 / .58)$

Mothers' version $(n=708) /$ Fathers' version $(n=663)$.

\section{Procedure}

According to several economic and industrial studies the region of the Principality of Asturias has been divided into eight geographic zones: Eo-Navia, Narcea, Avilés, Oviedo, Gijón, Caudal, Nalón and Oriente. Taking these zones into account, a simple random technique was used to select the sample, opting for two schools from each zone and considering simultaneously the school denomination: one public school and one private one were chosen. The research team contacted the principals of each school, explaining them the aim of the investigation. Once the principal approved the collaboration, each teacher gave his/her students an envelope with two questionnaires (father version and mother version) and an informative letter. In this document the main target of the research was explained and parents were asked for their cooperation. A telephone number and email contact were provided in case parents had any doubts or questions. When parents filled in the questionnaires, they returned them to teachers. After a few months, we contacted with schools again in order to collect all the questionnaires.

\section{Statistical analysis}

Structural equation modelling (SEM) was used to test the fit of fathers' and mothers' measurement model. The sample size was large, the multivariate normality was assumed, and skewness and kurtosis were calculated. All dimensions yielded values under 1 , in absolute value, so the normality criterion was met. We calculated fathers' and mothers' Pearson correlations, means and standard deviations. The analyses were carried out using M-Plus (Muthén \& Muthén, 2010) and SPSS 19. In these analyses, the covariance matrix and maximum-likelihood solutions were employed. In order to assess the fit of the hypothesized structural model, several values were calculated. First of all, Chi-squared test of significance $(\chi 2)$, taking into account that a good fit would provide a non-significant result at .05. However Chi-squared test has its limitations: normality assumption and it is also very sensitive to sample size. Because of these reasons, alternative indices are necessary to assess model fit: the comparative fit index $(C F I)$ an index which shows good fit when the value is greater than .90; the Tucker-Lewis index/non-normed fit in$\operatorname{dex}\left(T L I \_N N F I\right)$ in which the cutoff value has to be higher than .85 . Finally, the standardized root mean square residual value $(S R M R)$ and root mean square error of approximation (RMSE $A$ ) have a range from zero to 1.0, requiring values lower than .08 to consider the model. When these values are next to zero they indicate a good fit. Residual values have been examined to determine whether the means were around zero. We have also checked whether the frequency distribution was symmetrical. 


\section{Results}

Preliminary analyses have been made: Pearson linear correlation coefficients between the variables, means and standard deviations are presented in Table 3. After these analyses we carried out other procedures centered on aim testing. In order to explore the role of control dimension in the definition of fathers' and mothers' educational styles, we stated several models.

Table 3. Intercorrelations, Means, and Standard Deviations of fathers' and mothers' scores

\begin{tabular}{lcccccc}
\hline Dimensions of Model & 1 & 2 & 3 & 4 & $M$ & $S D$ \\
\hline Warmth/affection & - & $-.20 * *$ & - & $.21^{* *}$ & 29.32 & 2.70 \\
Hostility/aggression & $-.32^{* *}$ & - & - & $.16^{* *}$ & 4.37 & 1.44 \\
No indifference/no neglecta. & $.64^{* *}$ & $-.32^{* *}$ & - & - & - & - \\
Control & $.19^{* *}$ & $.13^{* *}$ & $.24^{* *}$ & - & 12.72 & 1.95 \\
$M$ & 21.39 & 8.78 & 19.56 & 8.80 & & \\
$S D$ & 2.59 & 2.12 & 3.02 & 1.85 & & \\
\hline
\end{tabular}

Note. Mothers' Intercorrelations $(n=2,166)$ are presented above the diagonal, and fathers' intercorrelations $(n=2,002)$ appear below the diagonal. Mothers' means and standard deviations are presented in the vertical columns, and fathers' means and standard deviations are presented in the horizontal rows.

${ }^{*} p<.05$; ${ }^{* *} p<.01$; *** $p<.001$.

\section{Fathers' educational style}

Figure 1 shows father's educational style. The indicators showed a good fit: $\chi 2(2,002,1)=0.541, p=.46, C F I=1.00$, TLI-NNFI $=1.00$, RMSE $A=.000$, SRMR $=.004$ (Hoyle, 1995; Hooper, 2008). Percentage of explained variance was $14 \%$ for hostility, $42.3 \%$ for non-indifference-neglect, and $5.60 \%$ for control.

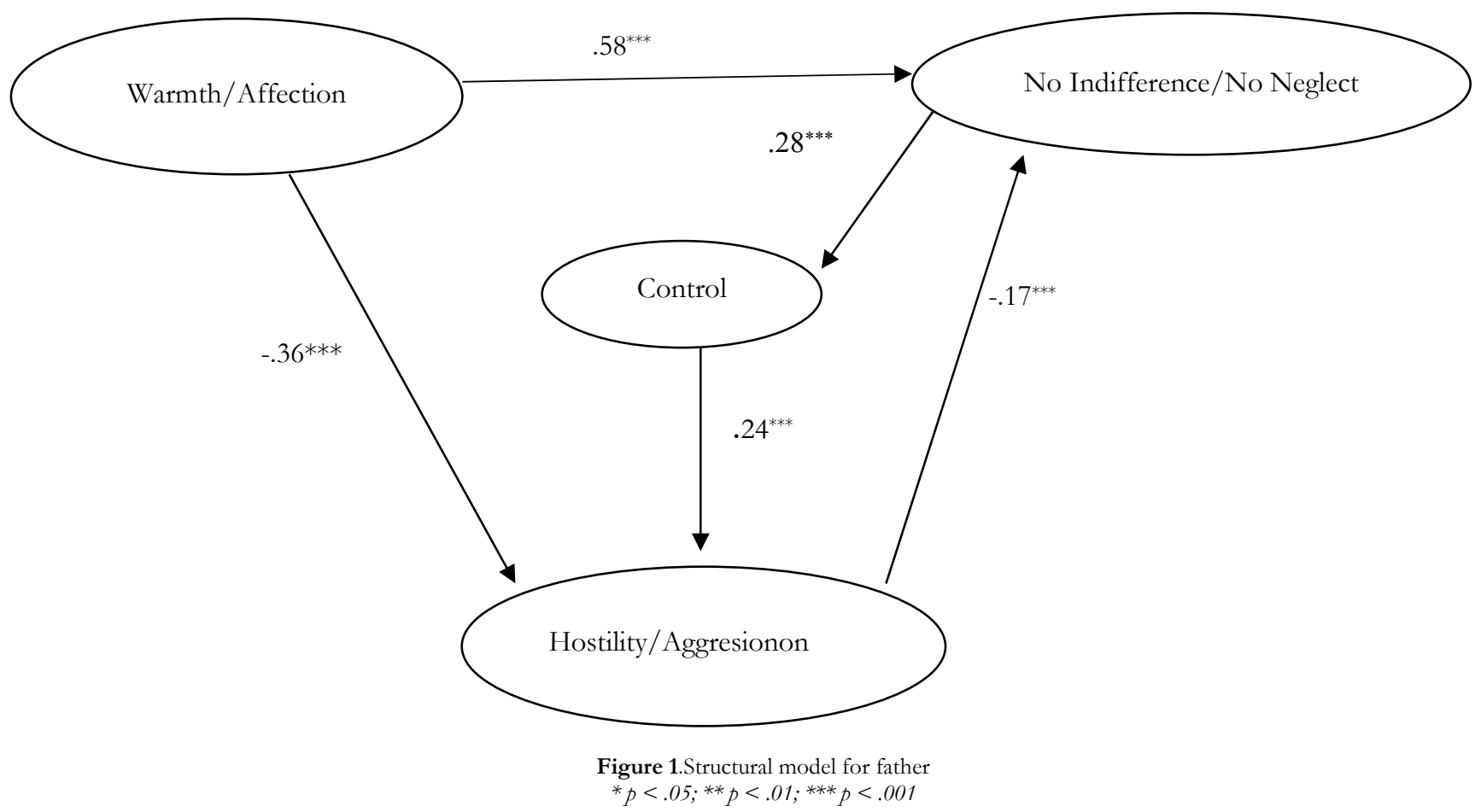

Our model intends to assess the mediator role of control in the other variables. This suggested model states that father's warmth/affection showed a significant path to no indifference/no neglect dimensions and to hostility dimension. Control dimension was a mediator between indifference/no neglect behaviors and hostility dimension, but it was necessary to considerer the direct path from hostility dimension to no indifference/no neglects behaviors to get the model fit (model 1). When this direct effect was not considered (model 2), the model did not fit (table 4). We also considered the direct influence of no indifference/no neglect to hostility/aggression, and we obtained that although the model showed a good fit, the indexes were a bit low (model 3). In 
addition, when a model where warmth/affection had direct influence on control was considered, the model did not fit.

Table 4. Fit indices for fathers' education style

\begin{tabular}{lccccccc}
\hline & $\chi^{2}$ & $D f$ & $p$ & $C F I$ & TLI & RMSEA & SRMR \\
\hline Model 1. & 0.54 & 1 & .46 & 1.00 & 1.00 & .00 & .00 \\
Model 2. & 84.04 & 2 & .00 & 0.94 & 0.84 & .14 & .05 \\
Model 3. & 4.77 & 1 & .03 & 0.99 & 0.98 & .04 & .01
\end{tabular}

Note. $D f=$ Degree of freedom; $C F I=$ Comparative fit index; TLI = TuckerLewis index; RMSE $A=$ Root mean square error of approximation; SRMR $=$ Standardized root mean square residual.

\section{Mothers' educational style}

Figure 2 shows the mothers' educational model which got the best fit (model 1), $\chi 2(2,166,1)=12.23, p=.00, C F I$ $=.94$, TLI-NNFI $=.88$, RMSE $A=.07$, SRMR $=.03$ (Hoyle, 1995; Hooper, 2008). Percentage of explained variance for control was $8 \%$. The influence of warmth on hostility was considered (model 2), but the fit was not better than in model 1. The principal difference among this model, it that the weights of warmth and hostility on control dimension were the same $(\beta=.20)$ and the significate path of warmth to hostility was -.11

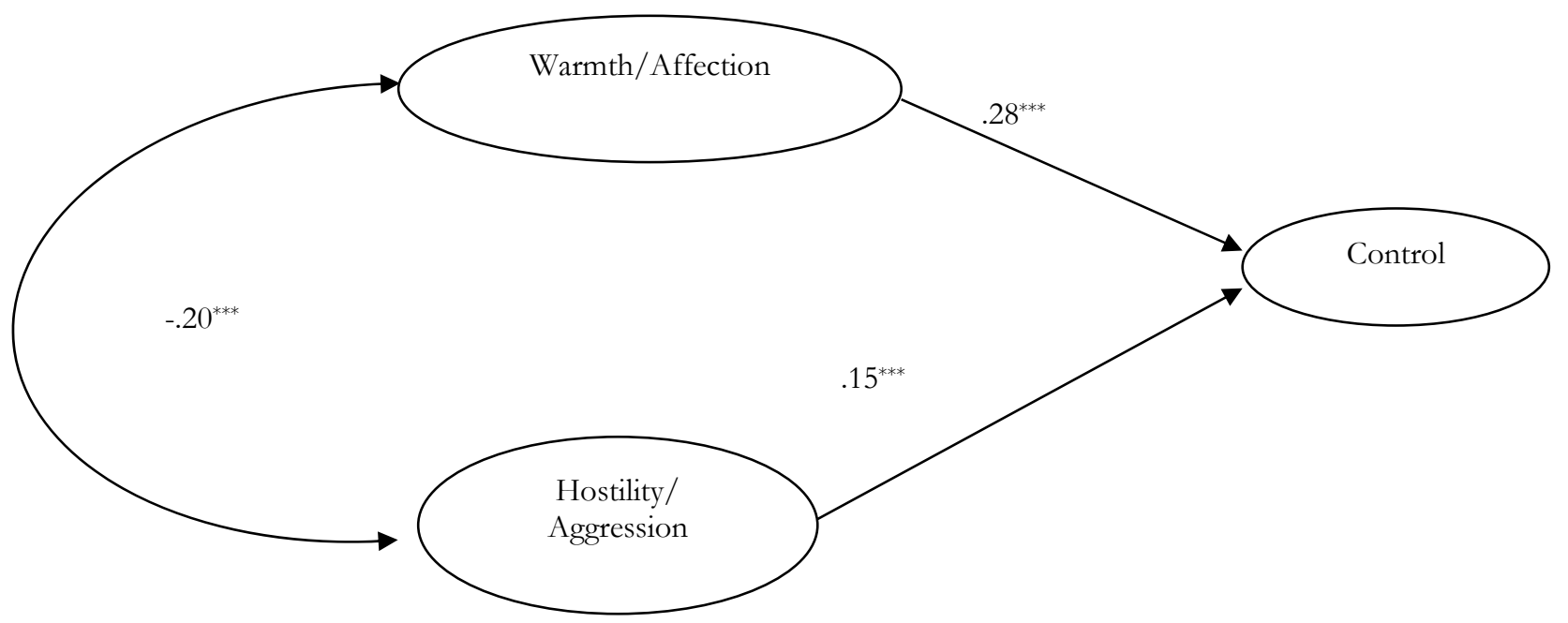

Figure 2.Structural model for mother.

${ }^{*} p<.05$; ** $p<.01$; *** $p<.001$

A third model in which the influence of the control dimension on warmth and hostility was evaluated, has been considered. In this third model (table 5), the values were similar to those observed in model 1 and model 2, but in model 3 the weights of the coefficients were lower.

Table 5. Fit indices for mothers' education style

\begin{tabular}{lccccccc}
\hline & $\chi^{2}$ & $D f$ & $p$ & $C F I$ & TLI & RMSEA & SRMR \\
\hline Model 1. & 12.23 & 1 & .00 & .94 & .88 & .07 & .03 \\
Model 2. & 12.23 & 1 & .00 & .96 & .88 & .07 & .03 \\
Model 3. & 12.03 & 1 & .00 & .96 & .88 & .07 & .03 \\
\hline
\end{tabular}

Note. $D f=$ Degree of freedom; CFI = Comparative fit index; TLI = TuckerLewis index; RMSEA = Root mean square error of approximation; SRMR $=$ Standardized root mean square residual.

\section{Discussion and conclusions}

We have to conclude that control behaviors correlate positively with warmth/affection ones. Fathers' and mothers' correlations among these dimensions are showing that parents can develop certain control behaviors which are compatible with affection conducts. In this sense, our results partially coincide with the conclusions obtained in other investigations. So, Deater-Deckard et al. (2011) concluded that high levels of warmth were associated with more control, but this association varied between the cultural groups studied in their research. For example, the data indicated relatively high levels of warmth but low control for the European American families. However, data also pointed out relatively highs levels of warmth and control for the African and Latino families. In a similar way, Barber et al. (2005) showed that parental support correlated significantly with behavioral and psychological control. Even though "these correlations among the three parenting dimensions are generally below the range in which concern about collinearity would be warranted" (Barber et al., 2005, 28). However Bean et al. (2006) did not find correlations among parenting dimensions, so parental support did not correlate with behavioral control.

We must also highlight important differences in fathers' and mothers' models referred to the role of control. In the case of fathers, control dimension is moderator among no indifference/neglect and hostility/aggression behaviors, but warmth dimension does not influence control dimension. Using Barber's dimensions, we can conclude that the psychological control (hostility/aggression dimension in Rohner's theory) is influenced by the level of behavioral control (control dimension in Rohner's theory) and by the level of parental supports (warmth/affection dimension in Rohner's theory). 
This is quite different in the mothers' model as long as the behavioral control (control dimension in Rohner's theory) is not a moderator; moreover, it is influenced by psychological control (hostility/aggression dimension in Rohner's theory) and by parental support (warmth/affection dimension in Rohner's theory). Both, in fathers and mothers, it is interesting to take into account that parental support (warmth/affection dimension in Rohner's theory) monitors psychological control (hostility/aggression dimension in Rohner's theory). These data can indicate that warmth/affection keep a positive relation with behavioral control and negative relation with psychological control (hostility/aggression). In this sense, our results are partially different to the conclusions obtained in other studies. So, Calafat et al. (2014) found negative correlations between Rohner's dimensions: warmth/affection and control. Besides, in the study developed by Bean et al. (2006), they corroborated that paternal support did not correlate with paternal behavioral control and maternal support did not correlate with maternal behavioral control.

The results obtained with our sample suggest that future research is necessary to analyze the interactions among parenting variables, that is: warmth dimension, psychological control dimension, and behavioral control dimension. Besides, it is necessary to analyze the interactions between parental dimensions and their associations with children's and adolescents' psychological and social adjustments.

On this last point, some researchers have analyzed the moderator effect between dimensions when they intend to explain their influence on psychological and social children's adjustment. Furthermore, in the research of Oliva, Parra, Sánchez - Queija \& López (2007) a high parental behavioral control was related with a lower consume of drugs in adolescents but only when it was paired with high warmth. Oliva et al. (2007) also concluded that the behavioral control was effective only when it was combined with warmth and that, without it, it did not prevent behavioral problems and was associated with emotional maladjustment.

\section{References}

Ali, S., Khaleque, A., \& Rohner, R.P. (2014). Influence of perceived teacher acceptance and parental acceptance on youth's psychological adjustment and school conduct: A cross-cultural meta-analysis. Cross-cultural Research, 49(2), 1-21. Doi: 10.1177/1069397114552769

Arim, R., \& Shapka, J. (2008). The impact of pubertal timing and parental control on adolescent problem behaviors. Journal of Youth Adolescence, 37 , 445-455. Doi: 10.1007/s10964-006-9158-y

Arim, R., Marshall, S., \& Shapka, J. (2010). A domain-specific approach to adolescent reporting of parental control. Journal of Adolescence, 33, 355366. Doi: $10.1016 /$ j.adolescence.2009.10.001

Aunola, K., \& Nurmi, J. (2004). Maternal affection moderates the impact of psychological control on a child's mathematical performance. Developmental Psychology, 40, 965-978. Doi: 10.1037/0012-1649.40.6.965

Barber, B.K., Stolz, H.E., Olsen, J.A., Collins, A., \& Burchinal, M. (2005). Parental support, psychological control, and behavioral control: Assessing relevance across time, culture, and method. Monographs of the Society for Research in Child Development, 70, 1-147. Doi: 10.1111/j.15405834.2005.00365.x
In relation to psychological control, Aunola \& Nurmi (2004) showed that the impact of psychological control on the development of children's math performance was moderated by mothers' affection. So, mothers' psychological control had a detrimental impact only when mothers simultaneously reported a high level of affection. Similarly, Barber et al. (2005) corroborated that the risk of the development of antisocial behaviors in adolescents is higher when parental psychological control is paired with high levels of perceived parental support. Gargurevich \& Soenens (2016) also found that parental responsiveness interacted with psychological control in the prediction of depressive symptoms in a sample of Peruvian adolescents. That is, responsiveness exacerbated the effects of psychological control on depressive symptoms.

To sum up, more research is needed to explain the paradoxical effects caused by the relation between the different parental dimensions. Barber et al. (2005) indicated that there was no empirical consistency of the interactions among these parenting dimensions.

One of the limitations of this study is its cross-sectional design; it would be very interesting to develop a longitudinal study to determine the influence of control in the other dimensions, by analyzing parental interactions in their child care. It would also be necessary to follow their behaviors since the start of the upbringing until children are twelve years old. Another limitation is that the outcomes of these educational models have not been determined. Thus, it would be useful to analyze the influence of these models on childrens' behavioral development. As in this study all the families were from Caucasian race, it is obvious that the sample is not heterogeneous in relation to race and ethnic group. It should be interesting to replicate this research with a sample of more diverse families. To reach this goal the research may be replicated in other Spanish regions such as Andalusia, Canary Islands, or other Spanish zones where a higher presence of other cultures can be found. Finally, in future studies the socioeconomic level of families must also be considered, in order to determine if this factor influences the relations of the variables of the model.

Bean, R., Barber, B., \& Crane, D. (2006). Parental support, behavioral control, and psychological control among African American youth. Journal of Family Issues, 27, 1335-1355. Doi: 10.1177/0192513X06289649

Bean, R.A., \& Northrup, J.C. (2009). Parental psychological control, psychological autonomy, and acceptance as predictors of self-esteem in Latino adolescents. Journal of Family Issues, 30(11), 1486-1504. Doi: 10.1177/0192513X09339149

Betancourt, D., \& Andrade, P. (2011). Control parental y problemas emocionales y de conducta en adolescentes. Revista Colombiana de Psicología, $20,27-41$.

Boudreault-Bouchard, A.M., Dion, J., Hains, J., Vandermeerschen, J., Laberge, L., \& Perron, M. (2013). Impact of parental emotional support and coercive control on adolescents' self-esteem and psychological distress: Results of a four-year longitudinal study. Journal of Adolescence, 36, 695-704. Doi: 10.1016/j.adolescence.2013.05.002.

Calafat, A., García, F., Juan, M., Becoña, E., \& Fernández-Hermida, J.R. (2014). Which parenting style is more protective against adolescents 
substance use? Evidence within the European context. Drug and Alcohol Dependence, 138, 185-192. Doi: 10.1016/j.drugalcdep.2014.02.705

Deater-Deckard, K. et al. (2011). The association between parental warmth and control in thirteen cultural groups. Journal of Family Psychology, 25, 790-794. Doi: $10.1037 /$ a0025120

Ferguson, Y.L., Kasser, T., \& Jahng, S. (2010). Differences in life satisfaction and school satisfaction among adolescents from three nations: the role of perceived autonomy support. Journal of Research on Adolescence, 21(3), 649-661. Doi: 10.1111/j.1532-7795.2010.00698.x

Fuentes, M., Alarcón, A., García, F., \& Gracia, E. (2015). Consumo de alcohol, tabaco, cannabis y otras drogas en la adolescencia: efectos de la familia y peligro del barrio. Anales de Psicología, 31(3), 1000-1007. Doi: 10.6018/analesps.31.3.183491

García, F., \& Gracia, E. (2009). Is always authoritative the optimum parenting style? Evidence from Spanish families. Adolescence, 44(173), 101-131.

García, F., \& Gracia, E. (2010). ¿Qué estilo de socialización parental es idóneo en España? Un estudio con niños y adolescentes de 10 a 14 años. Infancia y Aprendizaje, 33(3), 365-384.

Gargurevich, R., \& Soenens, B. (2016). Psychologically controlling parent and personality vulnerability to depression: a study in Peruvian late adolescents. Journal of Child Family Studies, 25(3), 911-921. Doi: 10.1007/s10826-015-0265-9

Grolnick, W., Raftery-Helmer, J., Flamm, E.S., Marbell, K.N., \& Cardemil, E.V. (2015). Parental provision of academic structure and the transition to middle school. Journal of Research on Adolescence, 25(4), 668-684. Doi: $10.1111 /$ jora. 12161

Khaleque, A. \& Rohner, R.P. (2002a). Perceived parental acceptancerejection and psychological adjustment: A meta-analysis of crosscultural and intracultural studies. Journal of Marriage and Family, 64, 5464. Doi: 10.1111/j.1741-3737.2002.00054.x

Khaleque, A., \& Rohner, R.P. (2002b). Reliability of measures assessing the pancultural association between perceived parental acceptance-rejection and psychological adjustment: a meta-analysis of cross-cultural and intracultural studies. Journal of Cross-Cultural Psychology, 33, 87-99. Doi: $10.1177 / 0022022102033001006$

Khaleque, A., \& Rohner, R.P. (2012a). Transnational relations between perceived parental acceptance and personality dispositions of children and adults: A meta-analytic review. Personality and Social Psychology Review, 16, 103-115. Doi: 0.1177/1088868311418986

Khaleque, A., \& Rohner, R.P. (2012b). Pancultural associations between perceived parental acceptance and psychological adjustment of children and adults: A meta-analytic review of worldwide research. Journal of Cross-Cultural Psychology, 43, 784-800. Doi: 10.1177/0022022111406120

Lansford, J., Laird, R., Pettit, G., Bates, J., \& Dodge, K. (2014). Mothers' and fathers' autonomy-relevant patenting: longitudinal links with adolescents' externalizing and internalizing behavior. Journal of Youth Adolescence, 43, 1877-1889. Doi: 10.1007/s10964-013-0079-2

McNeely, C.A., \& Barber, B. K. (2010). How do parents make adolescents feel loved? Perspectives on supportive parenting from adolescents in 12 cultures. Journal of Adolescent Research, 25, 601-631. Doi: $10.1177 / 0743558409357235$

Muthén, L., \& Muthén, B. (2010). Mplus. Statistical Analysis With Latent Variables. User's Guide. Los Angeles: Muthén and Muthén.

Oliva, A., Parra, A., Sánchez-Queija, I., \& López, F. (2007). Estilos educativos materno y paterno: evaluación y relación con el ajuste adolescente. Anales de Psicología, 23, 49-56.

Pastorelli, C. et al. (2016). Positive parenting and children's prosocial behavior in eight countries. Journal of Child Psychology and Psychiatry, 57(7), 824 834. Doi: $10.1111 /$ jcpp.12477

Pettit, G., Laird, R., Dodge, K., Bates, J., \& Criss, M. (2001). Antecedents and behavior-problem outcomes of parental monitoring and psychological control in early adolescence. Child Development, 72, 583-598.

Rohner, R. (2008a). Parental acceptance-rejection questionnaire (PARQ): Test Manual. In R. Rohner \& A. Khaleque (Eds.), Handbook for the Study of Parental Acceptance and Rejection (pp. 43-106). Storrs: Rohner Research Publications

Rohner, R. (2008b). Parental acceptance-rejection/control questionnaire (PARQ/Control): Test Manual. In R. Rohner \& A. Khaleque (Eds.), Handbook for the study of parental acceptance and rejection (pp. 137-186). Storrs: Rohner Research Publications.

Rohner, R., \& Carrasco, M. A. (2014). Teoría de la aceptación-rechazo interpersonal (IPARTheory): Bases conceptuales, método y evidencia empírica. Acción Psicológica, 11, 9-26.

Rohner, R.P., \& Khaleque, A. (2002). Parental acceptance-rejection and lifespan development: A universalist perspective. Online Readings in Psychology and Culture, 6, 1-10. Doi: 10.9707/2307-0919.1055

Rohner, R., \& Khaleque, A. (2008). Parental control scale (PCS): Test manual. In R. Rohner \& A. Khaleque (Eds.), Handbook for the study of parental acceptance and rejection (pp. 107-135). Storrs: Rohner Research Publications.

Rohner, R., \& Khaleque, A. (2010). Testing central postulates of parental acceptance-rejection theory (PARTheory): A meta-analysis of crosscultural studies. Journal of Family Theory \& Review, 2, 73-87. Doi: 10.1111/j.1756-2589.2010.00040.x

Rohner, R., Khaleque, A., \& Cournoyer, D. (2005). Parental acceptancerejection: theory, methods, cross-cultural evidence and implications. Ethos, 3, 299-334. Doi: 10.1525/eth.2005.33.3.29

Stone, L. et al. (2013). Does parental psychological control relate to internalizing and externalizing problems in early childhood? An examination using the Berkeley puppet interview. International Journal of Behavioral Development, 37(4), 309-318. Doi: 10.1177/0165025413490865

Wijsbroek, S.A., Hale III, W.W., Raaijmakers, Q.A.W., \& Meeus, W.H.J. (2011). The direction of effects between perceived parental behavioral control and psychological control and adolescents' self-reported GAD and SAD symptoms. European Child \& Adolescent Psychiatry, 20, 361-371. Doi: 10.1007/s00787-011-0183-3

(Article received: 07-06-2016; revised: 04-11-2016; accepted: 14-11-2016) 